\title{
Exploring Practical Optimal Topology for Reinforced Concrete Moment Resisting Frame Structures
}

\author{
Mehdi Babaei \\ Department of Civil Engineering, Faculty of Engineering, University of Zanjan, Zanjan, Iran
}

Email address:

mbabaei@znu.ac.ir

To cite this article:

Mehdi Babaei. Exploring Practical Optimal Topology for Reinforced Concrete Moment Resisting Frame Structures. American Journal of Civil Engineering. Vol. 3, No. 4, 2015, pp. 102-106. doi: 10.11648/j.ajce.20150304.12

\begin{abstract}
Topology optimization of reinforced concrete frames is one of a challenging issue in structural engineering. Frame structures, unlike trusses, must provide useable spaces. Architectural requirements affect greatly the layout of the structure and optimal spans, which are obtained theoretically. Sometimes optimal topologies are not possible for real projects because the calculated optimal spans do not provide architectural requirements. In this article, however, exploring for optimal spans for reinforced concrete frames is investigated considering the architectural limitations. For this purpose, three groups of spans, including $5.6 \mathrm{~m}, 7.5 \mathrm{~m}$ and $11.2 \mathrm{~m}$, are considered based on the parking limitations and then optimal practical sizing for the structures are obtained numerically for 5 -storey and 10 -storey structures. All models are estimated and considerable differences are shown by diagrams. The optimal topology is proposed for 5-storey to 10-storey buildings with different useable spans.
\end{abstract}

Keywords: Reinforced Concrete, Frame Structures, Optimization, Span, Topology

\section{Introduction}

Each year, millions square meters of buildings are constructed in the world. In 2012, it is been reported that the total buildings of about 260 million square meters have been built, which worth more than $\$ 63$ billion, while the oil income was about $\$ 25$ billion. Therefore, building construction is a big business and optimal design of buildings affects greatly on the global economy. Since the structural cost is about $\% 20-\% 30$ of total cost of the building, if structural optimization reduces only $\% 20$ of the costs, it will be about $\$ 3$ billion, which is about $\% 10$ of Iranian oil income.

Designers should define three aspects of the structure: topology, shape and size. Architects, usually, define topology and shape, then structural engineers calculate size of the elements based on the existing elements and dimensions. However, it is always a big problem to define optimal configuration satisfying all architectural requirements.

One of the vertical and lateral structural systems is moment resisting concrete frame (MRCF), which is most commonly used for mid and low-rise buildings in many countries. Different designs have been proposed and built based on the architectural requirements and structural designer's intuition and experience. Design of reinforced concrete (RC) frames with different ductility levels studied and cost-effective ductility levels proposed for RC buildings by Babaei [1].

One of the challenging issues in structural engineering is to find optimum structures. Researchers developed new methods for optimization and applied to frame and continuous structures [2, 3]. Evaluation of steel structures for optimal design investigated and optimum location and number for trusses obtained using evaluation of many different topologies [4]. A novel hybrid algorithm have been proposed in the literature and applied to topology optimization of steel braced frames [5]. Multiobjective optimization of steel moment resisting frames and braced frames using a hybrid evolutionary algorithm is studied and efficiency of the proposed algorithm reported [6].

Ketkukah et al. presented optimum design sensitivity of a two-bay one-storey RC plane frame [7]. Guerra and Kiousis presented a novel formulation aiming to achieve optimal design of RC structures [8]. Sharafi et al. worked on the optimization of RC structures and developed a heuristic approach for optimum cost and layout design of 3D reinforced concrete frames $[9,10]$. Thiruvengadam et al. studied on cost modeling of RC buildings for seismic effects [11].

This article aims to evaluate and compare different practical topologies for MRCF buildings and to obtain 
optimal structures, which not only provide cost-effective layout but also satisfy architectural requirements.

\section{Method and Numerical Models}

\subsection{Methodology}

In this study, to obtain practical optimal topology, which can be used in real projects, some models are considered based on the architectural requirements. The most important requirement for architects is providing parking area, so that the distance between columns has to provide this possibility.

Usually, two, three or four cars could be located between columns. For more than four cars, it needs very large spans for beams, which would not be cost effective. So, in this study only three types of spans for beams are considered as two, three and four cars could be parked next to each other. Floor area for all types is considered the same so that three types of spanning could be possible. Therefore, 23 meter dimension provides the requirements as detailed in the next section. To evaluate the effect of optimal span to the height of the structure, models of five and ten storey buildings are investigated. Therefore, in total, six models are designed and investigated for optimal topology exploration as detailed in the following.

\subsection{The Models}

Figure 1 displays 3D geometry of the ten-storey models. Table 1 illustrates the details of the geometry for five and ten storey models. The height of all stories is 3.5 meter and the structure's elements are assumed intermediate moment resisting reinforced concrete frames (IMRCF). For models with $11.2 \mathrm{~m}$ span, a joist is located in each direction at the middle of the span to provide stiffness for the roofs. Three types of spanning are considered as $\mathrm{A}, \mathrm{B}$, and $\mathrm{C}$ which define 5.6, 7.6, and 11.2 meter span.

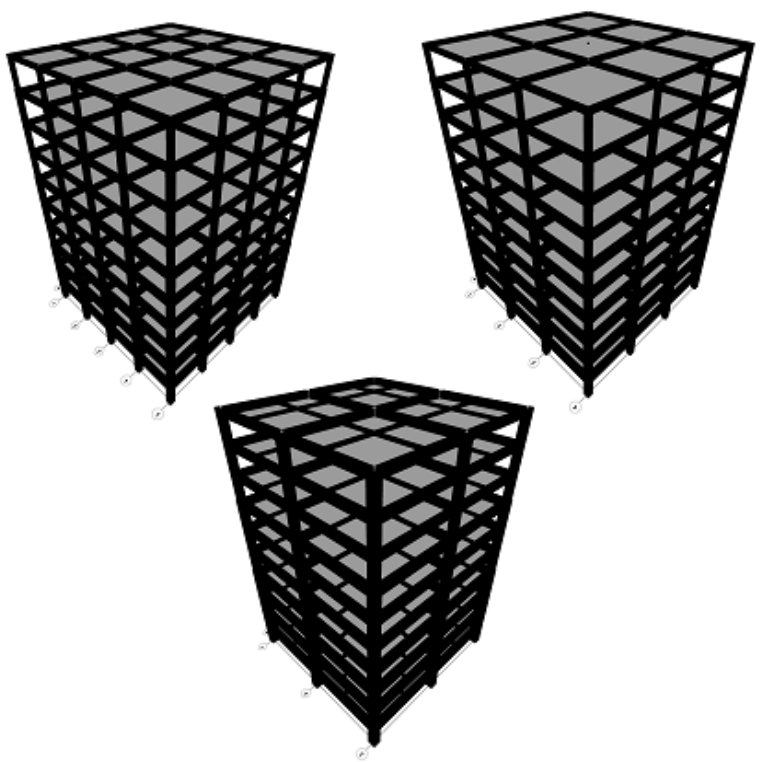

Figure 1. $3 D$ view for the ten-storey models.
Loading is calculated using Iranian National Building Code for loadings (INBC) [12] and a uniform dead of $D L=700 \mathrm{~kg} / \mathrm{m}^{2}$ and live load of $L L=200 \mathrm{~kg} / \mathrm{m}^{2}$ are applied to the models. Earthquake loads are calculated according to the Iranian Standard No. 2800-05 (ICPSRDB) [13], and INBC. Structural elements, however, are designed according to the ACI 318-02 [14].

Table 1. Geometry specifications of the models.

\begin{tabular}{lllll}
\hline Models & Storey Number & Span & Plan & Total Area \\
\hline 10SA & 10 & 5.6 & $23 * 23$ & 5290 \\
10SB & 10 & 7.5 & $23 * 23$ & 5290 \\
$10 \mathrm{SC}$ & 10 & 11.2 & $23 * 23$ & 5290 \\
$5 \mathrm{SA}$ & 5 & 5.6 & $23 * 23$ & 2645 \\
$5 \mathrm{SB}$ & 5 & 7.5 & $23 * 23$ & 2645 \\
$5 \mathrm{SC}$ & 5 & 11.2 & $23 * 23$ & 2645 \\
\hline
\end{tabular}

\section{Results and Discussion}

The first group of models contains five-storey IMRCF buildings and the second group includes ten-storey IMRCF buildings. Final cross sections for elements are obtained by trial and error procedure and structural elements are grouped considering requirements for easy construction.

Figures 2-3 display total required concrete for five-storey and ten-storey buildings per unit floor area. As shown in these figures, the difference between type $\mathrm{C}$ and other types are remarkable. In the other word, required concrete volume decreases rapidly from type $\mathrm{C}$ to $\mathrm{B}$, and then decreases slightly for type A.

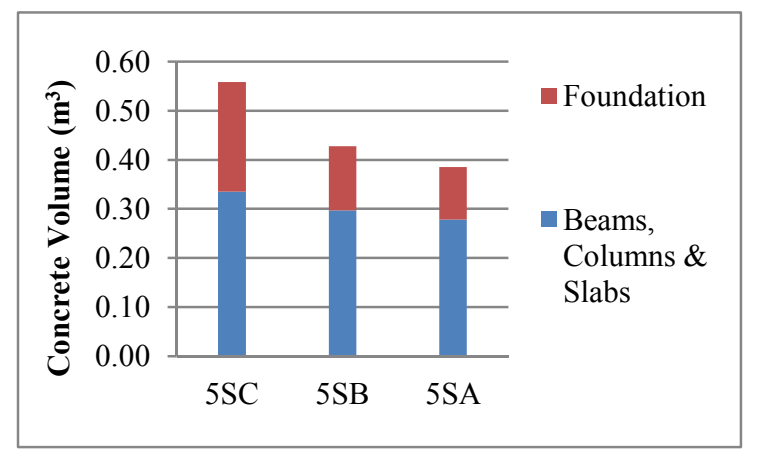

Figure 2. Total required concrete for five-storey models

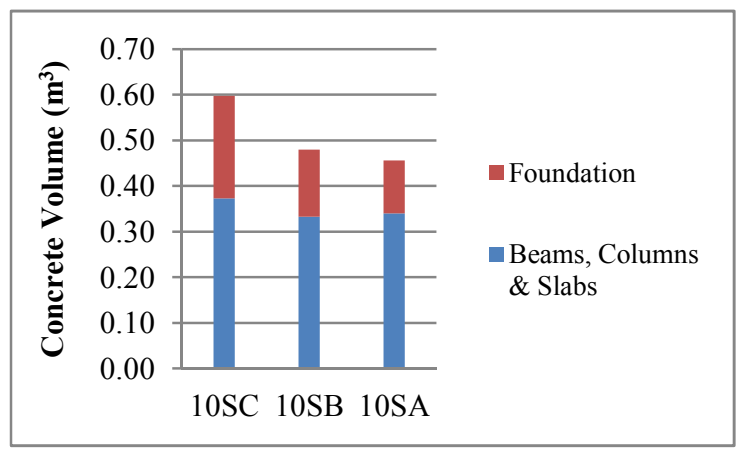

Figure 3. Total required concrete for ten-storey models.

Figures 4 and 5 display required reinforcement for five and ten-storey models, while figures 6 to 8 illustrates required 
concrete volume for structural elements in detail for different storey numbers. Required reinforcements for elements vs. storey number are illustrated in figures 9 to 13 .

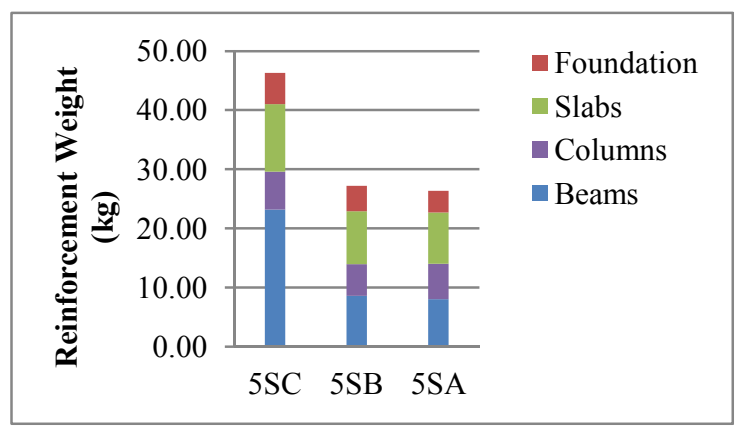

Figure 4. Total required reinforcement for five-storey models.

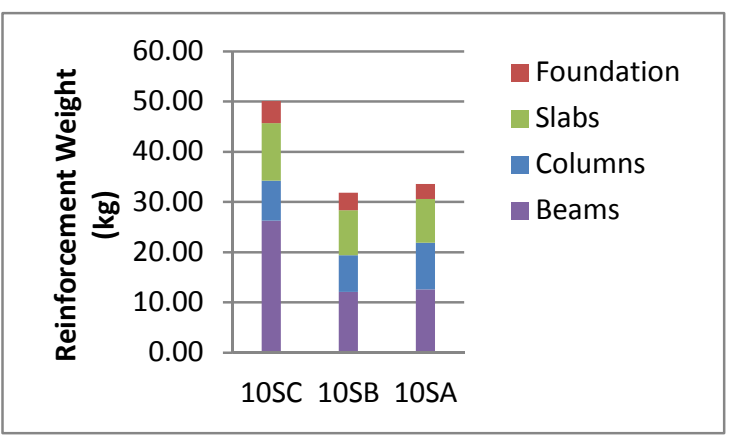

Figure 5. Total required reinforcement for ten-storey models.

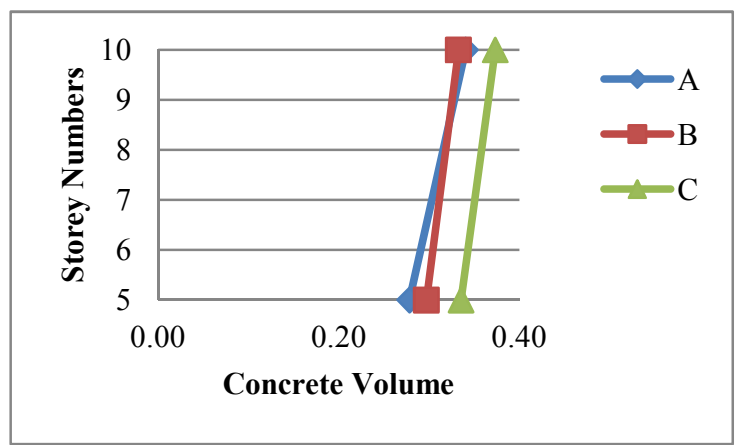

Figure 6. Required concrete for beams, columns and roofs vs storey number.

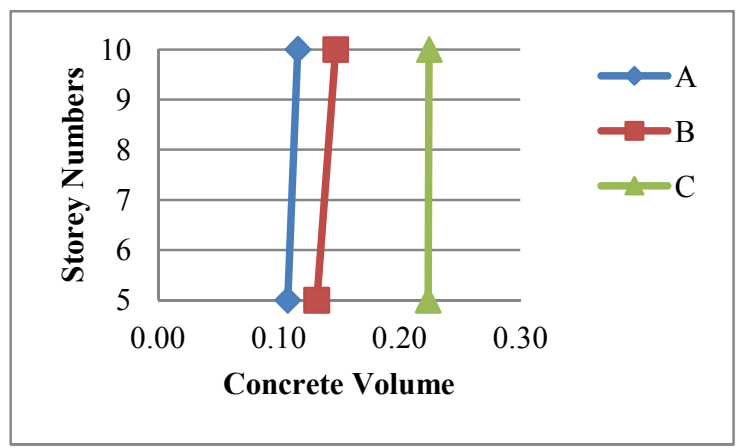

Figure 7. Required concrete for foundations vs. storey number.

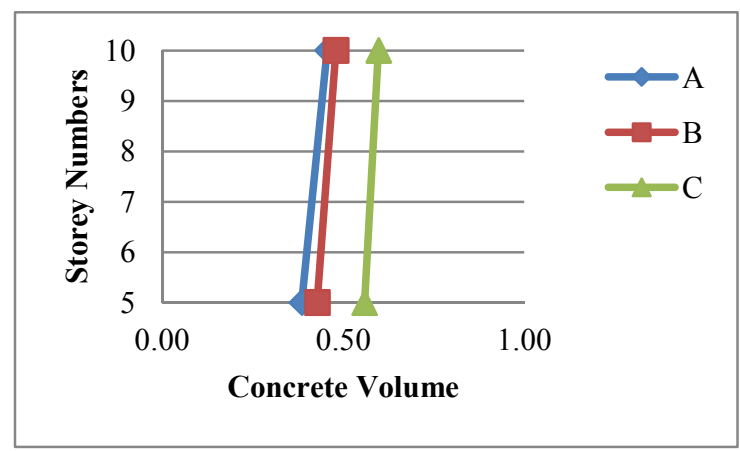

Figure 8. Total required concrete vs. storey number.

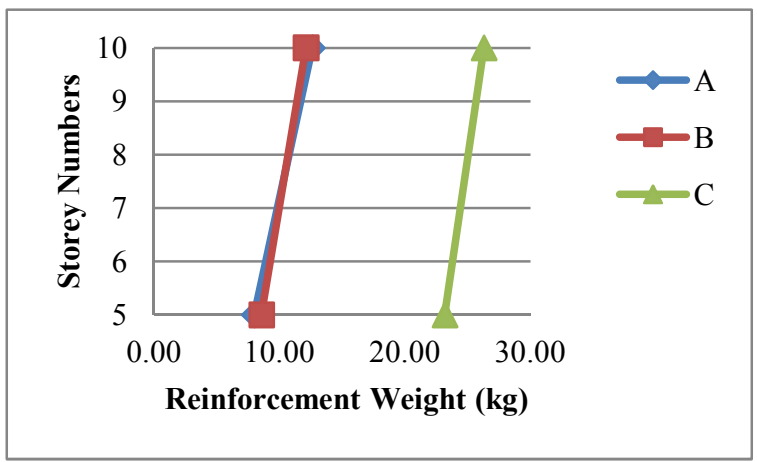

Figure 9. Required reinforcement for beams vs. storey number.

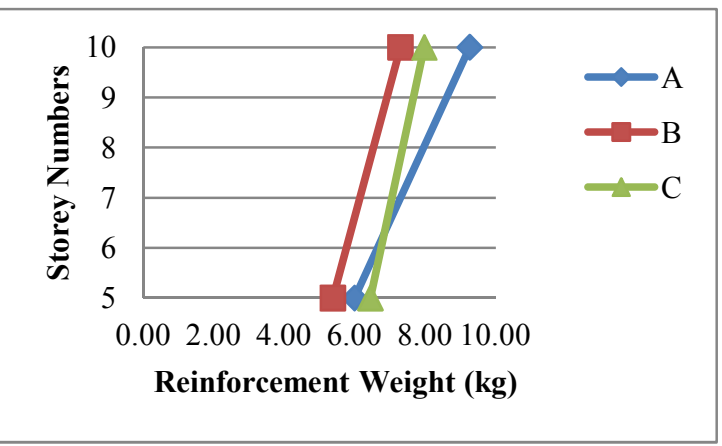

Figure 10. Required reinforcement for columns vs. storey number.

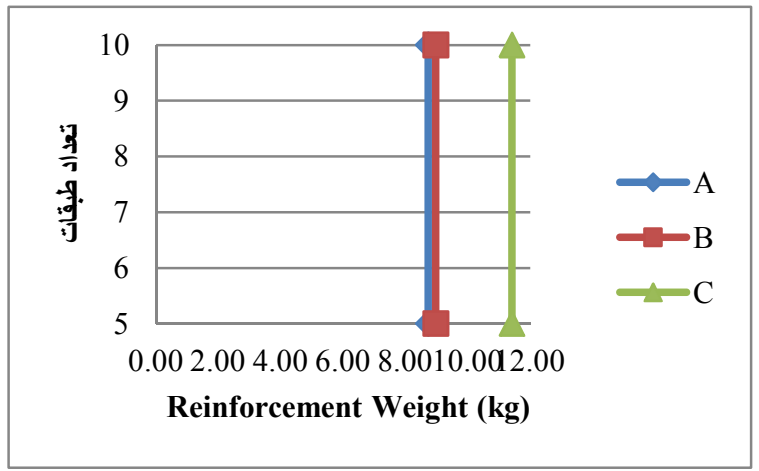

Figure 11. Required reinforcement for roof slabs vs. storey number. 


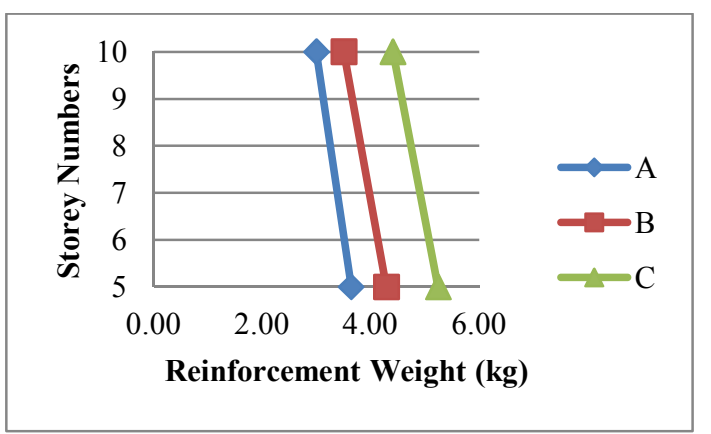

Figure 12. Required reinforcement for foundations vs. storey number.

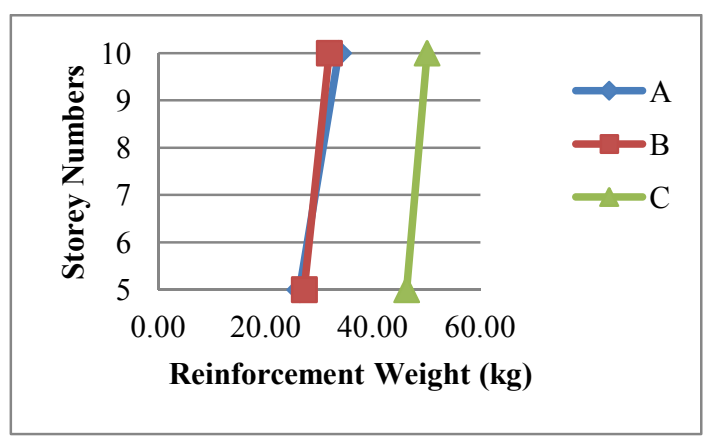

Figure 13. Total required reinforcement vs. storey number.

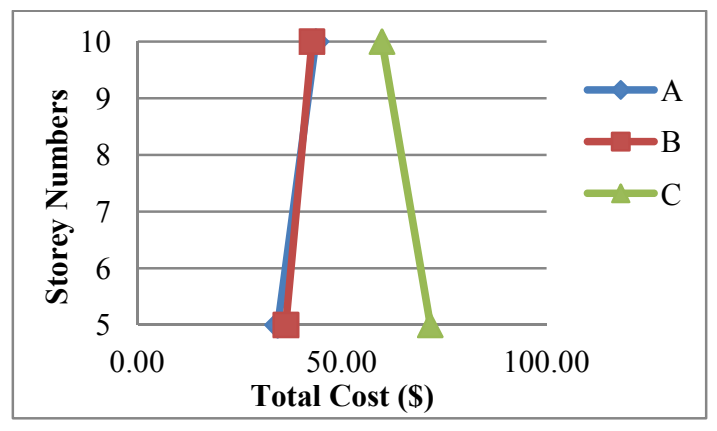

Figure 14. Total cost vs. storey number.

The total cost of models vs. storey numbers is illustrated in figure 14. As shown in this figure, type A is the optimal topology for five-storey buildings, while type B is optimal topology for ten-storey buildings. Optimal topologies for eight to nine-storey buildings are type $\mathrm{A}$ and $\mathrm{B}$, and there are two optimal solutions in this case.

Figure 14 also indicates that the total cost for type $\mathrm{C}$ decreases when the number of stories increases, and for tall buildings this type, $\mathrm{C}$, could be optimal. In the other words, optimal span increases when the number of stories increases. Moreover, the aspect ratio is an important parameter in this study and there is a relationship between this parameter and span length, which needs more study to obtain specific results.

Total cost, required reinforcement and concrete volume for 5SB model compared to the optimal model, 5SA, only shows only increases of $6 \%, 3 \%$, and $11 \%$ respectively. For model $5 \mathrm{SC}$, however, there is a rapid increase of about $64 \%, 76 \%$, and $45 \%$, compared to optimal model.

In ten-storey models, type B provides optimal topology, which includes buildings with $7.5 \mathrm{~m}$ spans. In type A compared to this type, total cost and required reinforcement increases about $2 \%$ and $5 \%$, while required concrete volume decreases $5 \%$. On the other hand, in type $\mathrm{C}$ total cost, required reinforcement and concrete volume increases $43 \%$, $57 \%$, and $25 \%$, respectively.

In buildings with $11.2 \mathrm{~m}$ spans (type C) large spans and low stiffness for frames require big beam sections to control displacements. Flexural moments of the beams are large and huge reinforcement is required, as illustrated in figure 9. There are small differences between types A and B for total cost and required materials, which specify $5.6 \mathrm{~m}$ and $7.5 \mathrm{~m}$ spanning.

\section{Conclusion}

In this article, satisfying architectural requirements practical optimal topology for buildings from five to ten-stories is investigated in the same floor area. Three type of spanning in assumed so that two, three and four cars could be located. Required materials and structural construction cost are evaluated to compare and obtain optimal buildings.

Although for five-storey buildings type A (5.6m spanning) and for ten-storey buildings type B (7.5m spanning) have the optimum total cost, however, there are only $3-5 \%, 4-10 \%$, and $2-6 \%$ difference (increase/decrease) between these types for the required concrete reinforcement, required concrete volume, and the total construction cost of various storey numbers. Type B, however, has a better architectural efficiency compared to type A, which can provide 9 parking locations in each direction, so, in general, buildings with $7.5 \mathrm{~m}$ spans provide optimum topology.

\section{Acknowledgment}

This article is part of a research, which was supported financially by the Ministry of Housing and Urban Development, grant no. 60477.

\section{References}

[1] Babaei M., "The economical effect of ductility levels on reinforced concrete frames design", American Journal of Civil and Structural Engineering, 2(1), (2015), 1-6.

[2] Sanaei E. and Babaei M., 2011, "Cellular automata in topology optimization of continuum structures", International Journal of Engineering, Science and Technology, 3 (4), (2011), 27-41.

[3] Sanaei E. and Babaei M., "Topology optimization of structures using cellular automata with constant strain triangles." International Journal of Civil Engineering, 10 (3), (2012), 179-188.

[4] Babaei M., "Multiobjective optimal number and location for steel outrigger-belt truss system", unpublished (under review).

[5] Babaei M. and Sanaei E., "Evaluation of HAG method in optimum topology design of steel braced frames", 1st Regional Congress on Civil Engineering, Malayer University, Iran, (2012). 
[6] Babaei M. and Sanaei E., "Multi-objective optimal design of braced frames using hybrid genetic and ant colony optimization algorithm", unpublished (under review).

[7] Ketkukah T. S., Abubakar I. and Ejeh S. P., "Optimum desing sensitivity of reinforced concrete frames", International Journal of Advanced Engineering Research and Technology, 2(5), (2014), 144-158.

[8] Guerra A. and Kiousis P. D., "Design optimization of reinforced concrete structures", Computers and Concrete, Vol. 3, No. 5 (2006) 313-334.

[9] Sharafi P., Hadi M.N.S. and Teh L.H., "Heuristic approach for optimum cost and layout design of $3 \mathrm{D}$ reinforced concrete frames", Journal of Structural Engineering, 138(7), (2012), 853-863.

[10] Sharafi, P., Hadi, M. N. and Teh, L. H., "A methodology for cost optimization of the layout design of multi-span reinforced concrete beams", Proceedings of the Fourteenth International
Conference on Civil, Structural and Environmental Engineering Computing (p. 124). United Kingdom: Civil-Comp Press, (2013).

[11] Thiruvengadam V., Wason J.C. and Gayathri L., "Cost modeling of reinforced concrete buildings designed for seismic effects", 13th World Conference on Earthquake Engineering, Canada, 2004.

[12] Iranian National Building Code (INBC), Part 6: Loadings, (2013).

[13] Standard No. 2800-05, Iranian Code of Practice for Seismic Resistant Design of Buildings, (2005).

[14] American Concrete Institute (ACI), Committee 318 Building Code Requirements for Structural Concrete (ACI 318-02) and Commentary (ACI 318R-02), Detroit, (2002). 